\title{
KONTRIBUSI DAN MOTIVASI KELUARGA KORBAN BENCANA SIGI DALAM BETERNAK AYAM KUB BANTUAN BALITBANGTAN
}

\section{The Contribution and Motivation of Sigi Disaster Victim Family in Cultivation of KUB Chicken Program}

\author{
Mardiana Dewi' ${ }^{1}$, Masyitah Muharni ${ }^{1}$, Wardi' ${ }^{1}$, dan Heni Sulistyawati Purwaning Rahayu ${ }^{1}$ \\ ${ }^{1}$ Balai Pengkajian Teknologi Pertanian Sulawesi Tengah \\ Email: mardianadewi11@ymail.com
}

\begin{abstract}
INTISARI
Bencana alam gempa bumi, likuefaksi, dan tsunami yang terjadi tanggal 28 September 2018 di Kota Palu, Kabupaten Sigi, dan Donggala telah menimbulkan kerusakan bahkan kehilangan tempat tinggal dan harta benda masyarakat di wilayah tersebut. Lahan pertanian yang menjadi sumber mata pencaharian tidak dapat digunakan kembali. Pada tahap pemulihan penanganan pasca bencana alam, pemerintah dan lembaga kemanusiaan membangun kembali sarana dan prasarana termasuk perekonomian korban bencana. Balai Pengkajian Teknologi Pertanian (BPTP) Sulawesi Tengah berperan serta dalam pemulihan sosial ekonomi korban bencana alam di Kabupaten Sigi melalui pengembangan ayam Kampung Unggul BALITBANGTAN (KUB) pedaging berbasis rumah tangga di hunian sementara (huntara) Desa Jono Oge, Kabupaten Sigi. Tujuan dari pengkajian ini adalah untuk mengetahui kontribusi dan motivasi keluarga korban bencana Sigi dalam beternak ayam KUB pedaging bantuan Balitbangtan berbasis rumah tangga. Kontribusi beternak ayam KUB pedaging dihitung dari persentase pendapatan ayam KUB pedaging terhadap pendapatan total rumah tangga sedangkan motivasi diukur dengan metode skoring menggunakan skala Likert. Berdasarkan hasil pengkajian diperoleh kesimpulan bahwa pendapatan korban bencana alam di huntara Desa Jono Oge, Kabupaten Sigi memiliki kontribusi peternak ayam KUB pedaging berbasis rumah tangga adalah $8,08 \%$ pada pendapatan $<$ Rp1.500.000,00 dan kontribusi 4,21\% pada kategori pendapatan Rp1.500.000,00 sampai Rp2.500.000,00. Motivasi korban bencana alam beternak ayam KUB pedaging yaitu pada kemudahan penjualan dan pemeliharaan.
\end{abstract}

Kata kunci: Ayam KUB Pedaging, Kontribusi, Korban Bencana, Motivasi

\begin{abstract}
The natural disasters of the earthquake, liquefaction, and tsunami that occurred on September 28, 2018 in Palu, Sigi, and Donggala have caused damage and even loss of residence and property of the people in the region. Agricultural land which was a source of livelihood could not be reused. During the recovery phase in the aftermath of natural disasters, the government and humanitarian agencies could rebuild facilities and infrastructure including the economy of disaster victims. Central Sulawesi Assessment Institute for Agricultural Technology (AIAT) participated in the socio-economic recovery of natural disaster victims in Sigi Regency through the development of superior BALITBANGTAN (KUB) chicken based on native households in temporary shelters in Jono Oge Village, Sigi Regency. The purpose of this study was to determine the contribution and motivation of Sigi disaster victims in raising KUB chickens based on households. The contribution of raising KUB chicken was calculated from the percentage of KUB chicken to total household income while motivation was measured by the scoring method using a Likert scale. Based on the results of the assessment, it was concluded that the income of victims of natural disasters at the Jono Oge Village in Sigi Regency had contribution contribution of raising KUB chickens based on households was $8.08 \%$ categorized at $<R p 1,500,000.00$ and $4.21 \%$ categorize at $R p 1,500,000.00$ - Rp2,500,000.00. The motivation of natural disaster victims for raising KUB chickens was on the ease of sales and maintenance.
\end{abstract}

Keywords: KUB Chicken, Contribution, Natural Disaster Victims, Motivation 


\section{PENDAHULUAN}

Bencana alam berupa gempa bumi, likuefaksi, dan tsunami telah mengakibatkan kerugian baik material maupun non-material yang tidak sedikit. Kerugian secara material meliputi kerusakan infrastruktur antara lain berupa bangunan serta sarana prasarana yang mengalami kerusakan mulai dari tingkat kerusakan ringan hingga berat (BPBD Donggala, 2018). Selain bencana gempa bumi dan likuefaksi, Kabupaten Sigi juga mengalami bencana tanah longsor dan banjir bandang di beberapa lokasi. Selain kerugian material tersebut, bencana alam juga memberikan kerugian non-material seperti kondisi psikologis para korban yang mengalami kesedihan dan kehilangan sehingga perlu dibangkitkan agar kembali berusaha mencari penghasilan bagi kehidupan keluarganya.

Kerugian material yang dirasakan langsung oleh petani yang terdampak bencana alam tidak hanya kehilangan rumah dan harta benda di dalamnya, melainkan juga lahan pertanian yang menjadi sumber pendapatan utamanya mengalami rusak berat dan tidak dapat digunakan kembali. Korban bencana alam yang tempat tinggalnya hilang atau rusak kini menempati hunian sementara (huntara) bantuan pemerintah maupun lembaga-lembaga kemanusiaan.

Tahapan penyelenggaraan penanggulangan bencana alam diawali dengan tanggap darurat yang berupa pemenuhan kebutuhan primer korban bencana seperti pangan. Saat ini pemulihan pada tahap perbaikan sarana dan prasarana umum serta pemulihan sosial ekonomi dan budaya yang secara rinci telah diatur pada Peraturan Kepala Badan Nasional Penanggulangan Bencana Nomor 4 Tahun 2008 tentang Pedoman Penyusunan Rencana Penanggulangan Bencana.

Balai Pengkajian Teknologi Pertanian (BPTP) Sulawesi Tengah pada tahun 2019 ikut serta dalam program pemulihan sosial ekonomi korban bencana alam di Kabupaten
Sigi melalui kegiatan Pengembangan Ayam Kampung Unggul Balitbangtan (KUB) Berbasis Rumah Tangga. Kegiatan ini merupakan bagian dari Program Bedah Kemiskinan Rakyat Sejahtera (BEKERJA) berbasis pertanian yang diluncurkan oleh Kementerian Pertanian melalui Peraturan Menteri Pertanian No.27/PERMENTAN/RC.120/5/ 2018.

Bantuan pemerintah kaitannya dengan Program Bekerja oleh Badan Penelitian dan Pengembangan Pertanian (BALITBANGTAN) adalah dalam rangka permasyarakatan inovasi penelitian pertanian. BALITBANGTAN memberikan tiga juta ekor bibit unggas lokal hasil penelitian pemuliaan yang mempunyai produktivitas tinggi yaitu ayam Kampung Unggul Balitbangtan (KUB) pedaging (BALITBANGTAN, 2018).

Ayam KUB pedaging berasal dari rumpun ayam kampung hasil penelitian Balai Penelitian Ternak BALITBANGTAN yang telah dilepas Kementerian Pertanian dengan SK Menteri Pertanian no. 274/Kpts/SR.120/2/2014. Ayam KUB pedaging memiliki keunggulan berupa produktivitas telur 160-180 butir/tahun dan bobot potong 800-1.000 gram selama pemeliharaan 10 minggu (Sartika, 2017). Laju pertumbuhan ayam KUB pedaging sampai umur 12 minggu masih mempunyai kecenderungan meningkat (Urfa et al., 2017).

Program pengembangan ayam KUB pedaging berbasis rumah tangga memberikan bantuan bibit ayam KUB pedaging sebanyak 20 ekor lengkap dengan kandang, peralatan, sarana produksi ternak (pakan, vaksin dan obat-obatan) serta pendampingan inovasi teknologi tatalaksana pemeliharaan ayam KUB pedaging oleh peneliti dan penyuluh. Pemeliharaan ayam KUB pedaging ini diharapkan dapat dikembangkan oleh warga korban bencana alam menjadi sumber pendapatan keluarga. Namun suatu teknologi dapat diterima dan berkembang apabila ada kontribusi teknologi tersebut secara nyata dalam peningkatan ekonomi dan sosial dari 
kondisi sebelumnya. Pengkajian ini bertujuan untuk mengetahui kontribusi dan motivasi keluarga korban bencana Sigi beternak ayam KUB pedaging bantuan BALITBANGTAN berbasis rumah tangga.

\section{MATERI DAN METODE}

Kajian dilaksanakan pada bulan April sampai dengan Agustus tahun 2019 di lokasi hunian sementara (huntara) korban bencana alam Desa Jono Oge, Kecamatan Sigi Biromaru, Kabupaten Sigi, Provinsi Sulawesi Tengah. Pengumpulan data dilakukan dengan metode survei menggunakan bantuan kuesioner. Responden dipilih secara purposive sampling sebanyak $10 \%$ dari keseluruhan penerima bantuan ayam KUB pedaging bantuan BALITBANGTAN berbasis rumah tangga dari Desa Jono Oge.

Data karakteristik kepala keluarga yang dikumpulkan berdasarkan umur, pendidikan terakhir, jumlah tanggungan keluarga, dan pengalaman beternak ayam kampung. Data kontribusi beternak ayam KUB pedaging meliputi sumber serta jumlah pendapatan sebelum dan setelah bencana alam. Data motivasi berupa keberlanjutan usaha dan indikator motivasi beternak ayam KUB pedaging dari segi ketersediaan modal, ketersediaan Sarana Produksi Peternakan (SAPRONAK), kepastian pasar, keuntungan, kemudahan pemeliharaan, serta ketahanan penyakit.

Kontribusi pendapatan dari beternak ayam KUB pedaging terhadap pendapatan keluarga korban bencana alam adalah besarnya sumbangan atau bagian pendapatan dari usaha tani ayam KUB pedaging terhadap seluruh pendapatan keluarga. Untuk mengetahui besarnya kontribusi usaha beternak ayam KUB pedaging dihitung dengan menggunakan rumus menurut Paulus et al. (2015) sebagai berikut:

Kontribusi $=\frac{\text { Pendapatan Usahatani Ayam KUB }}{\text { Total Pendapatan Keluarga }}$
Data motivasi yang diperoleh dianalisis menggunakan metode skoring menggunakan skala Likert berjenjang lima. Jenjang pengukuran yang digunakan adalah sangat setuju, setuju, ragu-ragu, kurang setuju dan tidak setuju. Skala Likert yang mengukur sifatsifat (traits) individu dengan menggunakan skor total dari butir pertanyaan adalah skala pengukuran interval (Budiaji, 2013). Dengan interval penilaian:

$\begin{array}{lll}\text { Indeks 0\%-19,99\% } & : & \text { sangat tidak } \\ & & \text { setuju } \\ \text { Indeks } 20 \%-39,99 \% & : & \text { tidak setuju } \\ \text { Indeks 40\%-59,99\% } & : & \text { ragu-ragu } \\ \text { Indeks 60\%-79,99\% } & : & \text { setuju } \\ \text { Indeks } 80 \%-100 \% & : & \text { sangat setuju }\end{array}$

\section{HASIL DAN PEMBAHASAN}

\section{Karakteristik Wilayah dan Responden}

Desa Jono Oge merupakan salah satu desa yang terletak di Kabupaten Sigi Sulawesi Tengah. Sebelum bencana alam, Desa Jono Oge dikategorikan sebagai desa swasembada yaitu desa yang sudah maju dan mengembangkan sumber daya untuk pembangunan desanya. Desa tersebut mempunyai luas sebesar 52,71 $\mathrm{km}^{2}$ yang setara dengan $18,20 \%$ terhadap luas kecamatan. Jumlah penduduknya sebanyak 2.817 jiwa, yang terdiri dari laki-laki 1.460 orang dan perempuan 1.357 orang (Badan Pusat Statistik, 2019).

Area Jono Oge merupakan daerah terluas yang mengalami pergerakan tanah dengan luas kurang lebih $2,1 \mathrm{~km}^{2}$. Area ini merupakan daerah pertanian dimana hanya sekitar kurang dari 5\% area yang menjadi pemukiman penduduk. Mekanisme pergerakan tanah yang terjadi di Jono Oge mirip dengan yang terjadi di Petobo Palu dimana pergerakan berakhir di saluran irigasi (Tim Pusat Studi Gempa Nasional, 2018).

Hasil pengkajian menunjukkan bahwa data rataan umur penerima bantuan ayam KUB pedaging skala rumah tangga di Desa Jono Oge adalah 42 tahun, yang mana masih 
berada pada umur produktif. Menurut Sudana dan Subagyono (2012) umur berpengaruh nyata terhadap peluang adopsi inovasi PTT. Program tersebut hendaknya diprioritaskan kepada kelompok tani dengan porsi anggota yang berumur relatif muda lebih banyak dibandingkan dengan anggota berumur lanjut.

Pengembangan ayam KUB pedaging berbasis rumah tangga BPTP Sulawesi Tengah adalah kegiatan diseminasi dengan pendekatan partisipatif sehingga diharapkan pelaksana kegiatan dapat berperan aktif dalam proses adopsi dan penyebaran informasi ayam KUB pedaging. Budiwan (2018) menambahkan bahwa keikutsertaan orang dewasa dalam belajar memberikan dampak positif dalam melakukan perubahan hidup ke arah yang lebih baik.

Rataan pendidikan terakhir responden adalah jenjang SMP dengan jumlah tanggungan dua orang. Pengalaman beternak ayam kampung rata-rata 4 tahun dengan kepemilikan berkisar 2 sampai 10 ekor per rumah tangga. Sebelum beternak ayam KUB pedaging, responden telah memelihara ayam kampung sebagai usaha sambilan.

\section{Kontribusi Usaha Ayam KUB Pedaging Terhadap Pendapatan Rumah Tangga}

Distribusi pendapatan responden di Desa Jono Oge diklasifikasikan menjadi empat kriteria yang secara rinci disajikan pada Tabel 1. Sebelum bencana alam, pendapatan responden berada pada persentase tertinggi dengan angka Rp1.500.000,00 sampai Rp2.500.000,00. Responden pada umumnya bermata pencaharian sebagai petani.
Komoditi utamanya adalah pangan dan hortikultura.

Berdasarkan hasil wawancara di lapangan, sebelum bencana alam 53\% responden bekerja sebagai petani, $27 \%$ wiraswasta, $13 \%$ tukang batu, dan $7 \%$ serabutan. Namun setelah bencana 50\% responden tidak memiliki pekerjaan tetap atau serabutan, lahan pertanian yang tidak dapat dikelola kembali karena irigasi rusak berat.

Persentase responden yang memiliki pendapatan di bawah Rp1.500.000,00 sebesar $73,33 \%$. Profesi yang dilakukan sebagian besar adalah menjadi buruh pembangunan huntara maupun perbaikan rumah warga. Sejalan dengan pendapat Tondi (2019) yang menyatakan bahwa agar dapat terus bertani, para petani di Desa Jono Oge mencari lahan pertanian di desa sekitar yaitu Lolu, Pombewe, Solowe, Pedagi, Watunonju dan Kalukubula dengan sewa lahan Rp5.000.000,00 sampai Rp10.000.000,00 setiap hektar per tahun.

Kondisi tersebut menyebabkan korban bencana membutuhkan modal dan diharapkan ada solusi keringanan pembayaran setelah panen. Pemerintah juga diharapkan dapat segera memperbaiki sarana dan prasarana di Desa Jono Oge. Umaroh dan Ritohardoyo (2016) menambahkan bahwa strategi penghidupan masyarakat pasca bencana tanah longsor lebih pada aktivitas memulihkan perekonomian selain itu masyarakat berperan aktif dalam mendukung pemerintah untuk melakukan penanganan bencana yang lebih baik.

Tabel 1. Distribusi Pendapatan Peternak Ayam KUB Skala Rumah Tangga Sebelum dan Sesudah Bencana Alam di Desa Jono Oge, Sigi

\begin{tabular}{cccc}
\hline No & Pendapatan Total per Bulan (Rp) & Sebelum Bencana (\%) & Setelah Bencana (\%) \\
\hline 1 & $<1.500 .000$ & 13,33 & 73,33 \\
2 & $1.500 .000-2.500 .000$ & 46,67 & 26,67 \\
3 & $2.500 .000-3.500 .000$ & 26,67 & - \\
4 & $>3.500 .000$ & 13,33 & - \\
\hline & Jumlah & 100,00 & 100,00 \\
\hline
\end{tabular}


Analisis usaha ayam KUB pedaging berbasis rumah tangga di Desa Jono Oge dilakukan untuk mengetahui keuntungan yang dapat diperoleh oleh masing-masing rumah tangga. Ayam Kampung Unggul BALITBANGTAN pedaging yang dipelihara rumah tangga sebanyak 20 ekor selama 70 hari dengan tetap memperhitungkan biaya tenaga kerja. Keuntungan yang diperoleh adalah Rp205.000,00 per periode dengan mortalitas sebesar $5 \%$ yang secara rinci dapat dilihat pada Tabel 2.

Tabel 2. Analisis Usaha Ayam KUB Pedaging Berbasis Rumah Tangga di Desa Jono Oge, Sigi

\begin{tabular}{lc}
\hline \multicolumn{1}{c}{ Uraian } & Nilai (Rp) \\
\hline Penyusutan Kandang dan Peralatan 70 hari & 20.000 \\
Beli DOC 20 ekor @ Rp. 8.500 per ekor & 255.000 \\
Pakan Complete Feed & 99.600 \\
Pakan Finisher & 190.400 \\
Obat-obatan vitamin dan vaksin & 15.000 \\
Tenaga Kerja & 70.000 \\
\hline Total Biaya & 650.000 \\
\hline Penjualan 19 ekor@ Rp. 45.000 per ekor & 855.000 \\
\hline Keuntungan selama 70 hari & 205.000 \\
\hline R/C ratio & 1,32 \\
\hline Kontribusi keuntungan per bulan & 87.850 \\
\hline Titik Impas Produksi (ekor) & 14 \\
\hline Titik Impas Harga & 34.200 \\
\hline
\end{tabular}

Keuntungan yang diperoleh dari beternak ayam KUB pedaging sebesar Rp87.850,00 yang diperoleh dari hasil pengurangan seluruh biaya produksi selama satu periode yang diasumsikan menjadi per bulan. Dari analisis yang dilakukan, diketahui kontribusi usaha ayam KUB Pedaging terhadap pendapatan rumah tangga di Desa Jono Oge pada kategori kurang dari Rp1.500.000,00 adalah 8,08\% dan kategori pendapatan antara Rp1.500.000,00 sampai Rp2.500.000,00 adalah 4,21\% (Tabel 3).
Semakin tinggi pendapatan rumah tangga korban bencana maka semakin rendah kontribusi usaha ayam Kampung Unggul BALITBANGTAN pedaging yang dihasilkan. Menurut Elizabeth dan Rusdiana (2012), usaha ternak ayam buras masih bersifat subsistem dan masih bersifat tabungan/investasi, dimana ternak akan dijual saat petani memerlukan kebutuhan yang mendesak. Namun demikian, peran dan fungsi ternak ayam di pedesaan cukup menunjang kesejahteraan petani di pedesaan.

Tabel 3. Kontribusi Usaha Ayam KUB Pedaging Terhadap Pendapatan Rumah Tangga di Desa Jono Oge, Sigi

\begin{tabular}{cccc}
\hline No & Pendapatan total per bulan (Rp) & Setelah Bencana (\%) & Kontribusi (\%) \\
\hline 1 & $<1.500 .000$ & 73,33 & 8,08 \\
2 & $1.500 .000-2.500 .000$ & 26,67 & 4,21 \\
3 & $2.500 .000-3.500 .000$ & - & - \\
4 & $>3.500 .000$ & - & - \\
\hline & Jumlah & 100,00 & - \\
\hline
\end{tabular}

Apabila dicermati pada Tabel 3 maka ternak ayam KUB pedaging di lokasi huntara korban bencana ini sudah memberikan tambahan pendapatan meskipun tidak sebesar pendapatan utama keluarga. Hal ini karena pemeliharaan ayam tersebut masih berskala rumah tangga dan belum dikelola secara serius sebagai usaha komersial. Potensi 
pengembangan dan keberlanjutan usaha sangat bergantung pada faktor sosial ekonomi dengan dukungan inovasi teknologi untuk peningkatan produksi.

\section{Motivasi Korban Bencana Sigi Beternak Ayam KUB Pedaging Berbasis Rumah Tangga}

Motivasi pada dasarnya adalah kondisi mental yang mendorong dilakukannya suatu tindakan yang mengarah kepada pencapaian kebutuhan (Alam at al., 2014). Responden memberikan penilaian terhadap indikator motivasi selama melakukan budidaya ayam KUB pedaging, sehingga dapat diketahui halhal yang dapat mempengaruhi keberlanjutan usaha dan dapat memberikan masukan kepada program pengembangan ayam KUB pedaging kedepannya. Motivasi responden peternak Ayam KUB pedaging skala rumah tangga di Desa Jono Oge (Tabel 4).

Berdasarkan hasil pengkajian di lapangan, responden tidak setuju apabila usaha budidaya ayam Kampung Unggul BALITBANGTAN pedaging dikatakan tidak membutuhkan modal, karena modal digunakan untuk penyediaan sarana dan prasarana. Kandang dan peralatan yang digunakan disesuaikan dengan jumlah ayam yang akan dipelihara. Alternatif kebijakan yang dapat diambil untuk keberlanjutan pengembangan ayam KUB pedaging salah satunya adalah dengan membangun dan mendorong kelembagaan KEP/Koperasi serta memberikan fasilitas untuk penunjang produksi seperti DOC, pakan, vitamin, obatobatan (Prawiranegara at al., 2019).

Faktor-modal sebagai faktor yang diduga menjadi determinasi peluang adopsi teknologi budidaya ayam KUB pedaging juga terjadi di wilayah Papua Barat yang juga menjalankan program pengembangan ayam KUB pedaging, yaitu adanya keharusan untuk memelihara ayam KUB pedaging secara intensif, dengan penyediaan pakan secara teratur (Ijah dan Altandjung, 2019).

Tabel 4. Motivasi Korban Bencana Sigi Beternak Ayam KUB pedaging di Desa Jono Oge, Sigi.

\begin{tabular}{clcc}
\hline No & \multicolumn{1}{c}{ Uraian } & Nilai Indeks (\%) & Interval Penilaian \\
\hline 1 & Modal terjangkau & 37,33 & tidak setuju \\
2 & Pakan dan Obat-obatan mudah diperoleh & 37,33 & tidak setuju \\
3 & Ayam KUB mudah dipasarkan & 77,33 & setuju \\
4 & Keuntungan penjualan ayam KUB & 36,00 & tidak setuju \\
5 & Kemudahan pemeliharaan ayam KUB & 65,00 & setuju \\
6 & Ayam KUB tahan penyakit & 50,67 & ragu-ragu \\
\hline
\end{tabular}

Responden juga tidak setuju apabila dikatakan bahwa pakan dan obat-obatan untuk beternak ayam KUB pedaging mudah diperoleh. Pakan yang diberikan kepada ayam KUB pedaging terdiri dari complete feed berupa pakan starter dan pakan finisher. Pakan finisher merupakan campuran dari pakan komersil pabrikan (konsentrat), jagung giling dan dedak padi.

Dari hasil wawancara diketahui bahwa ketersediaan bahan baku pakan saat ini sulit didapatkan karena kurangnya produksi komoditi pakan ternak. Motivasi dengan indikator bahwa ayam KUB pedaging mudah dipasarkan memperoleh respon setuju. Ayam KUB pedaging skala rumah tangga bisa dijual kepada pedagang pengepul yang ada di wilayah Kecamatan Sigi Biromaru. Selain itu, huntara Jono Oge yang terletak di daerah Sigi Biromaru berdekatan dengan usaha kuliner ayam kampung khas Kabupaten Sigi yaitu Ayam Panggang Biromaru. Kuliner ini banyak diminati oleh warga dan tamu luar provinsi yang sedang berkunjung ke Kota Palu.

Motivasi dengan indikator keuntungan penjualan ayam KUB pedaging mendapat respon tidak setuju. Keuntungan yang diperoleh dari penjualan ayam KUB pedaging 
dirasa masih sangat rendah. Harga jual dari pedagang pengepul Rp45.000,00 dinilai masih sangat rendah. Harga jual tersebut dapat ditingkatkan jika peternak menjual ayam KUB pedaging kepada konsumen langsung secara eceran atau pada hari-hari besar keagamaan sehingga peternak perlu membuat strategi waktu pemeliharaan yang berorientasi pasar.

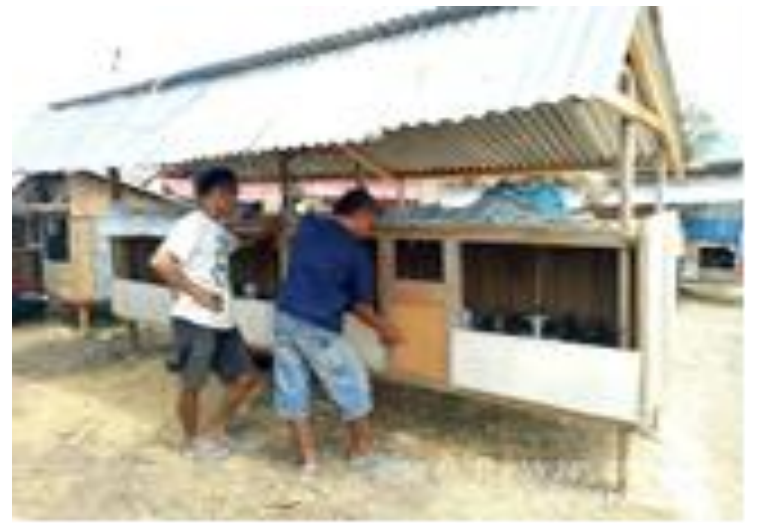

Gambar 1. Kandang Ayam KUB Pedaging Skala Rumah Tangga di Huntara Desa Jono Oge.

Responden setuju pada indikator kemudahan pemeliharaan ayam KUB pedaging. Ayam Kampung Unggul BALITBANGTAN pedaging dipelihara dari DOC hingga umur 70 hari. Pada proses pemeliharaan tidak memerlukan penanganan yang rumit, dapat dilakukan di sela-sela aktivitas lainnya seperti pemberian pakan pagi dan sore, perawatan kandang dan peralatan. Indikator yang terakhir adalah peternak ragu-ragu jika ayam KUB pedaging tahan penyakit. Kandang ayam KUB pedaging di huntara Jono Oge berada di areal terbuka dan lingkungan yang tidak mendukung, sehingga dapat mengakibatkan ayam KUB pedaging rentan terserang penyakit.

\section{KESIMPULAN DAN SARAN}

\section{Kesimpulan}

Pendapatan korban bencana alam di huntara Desa Jono Oge Kabupaten Sigi kategori kurang dari Rp1.500.000,00 memberikan kontribusi kepada peternak ayam KUB pedaging bantuan BALITBANGTAN berbasis rumah tangga sebesar 8,08\%, sedangkan pada kategori pendapatan antara Rp1.500.000,00 sampai Rp2.500.000,00 sebesar 4,21\%. Motivasi korban bencana alam untuk keberlanjutan usaha ayam KUB pedaging yaitu pada kemudahan penjualan dan pemeliharaan ayam KUB pedaging.

\section{Saran}

Saran yang dapat diberikan dari hasil penelitian ini adalah untuk meningkatkan kontribusi peternak ayam KUB pedaging terhadap pendapatan rumah tangga korban bencana alam dapat dilakukan dengan meningkatkan populasi ayam KUB pedaging yang dipelihara. Untuk mengurangi tingginya biaya produksi maka pengadaan sarana produksi ternak berupa DOC, pakan, vitamin dan obat-obatan sebaiknya dikelola melalui kelompok.

\section{UCAPAN TERIMA KASIH}

Ucapan terima kasih penulis sampaikan kepada responden peternak ayam KUB Berbasis Rumah Tangga di Huntara Desa Jono Oge Kabupaten Sigi atas informasi dan waktu yang telah diluangkan selama pengkajian.

\section{DAFTAR PUSTAKA}

Alam, A., Dwijatmiko, S dan Sumekar, W. 2014. Motivasi Peternak Terhadap Aktivitas Budidaya Ternak Sapi Potong di Kabupaten Buru Provinsi Maluku. Jurnal Agromedia. 32 (2):75-89.

Badan Litbang Pertanian. 2018. Petunjuk Teknis Program Bedah Kemiskinan Rakyat Sejahtera (Program Bekerja). Kementerian Pertanian. Jakarta.

Badan Penanggulangan Bencana Daerah (BPBD) Kabupaten Donggala. 2018. Laporan Perkembangan Penanganan Bencana Gempa Bumi dan Tsunami (28 September 2018). Pemerintah Daerah kabupaten Donggala. Provinsi Sulawesi Tengah.

Badan Pusat Statistik (BPS). 2019. Kecamatan Sigi Biromaru dalam Angka. Qalamuna. 10 (2):107-135. 
Budiaji, W. 2013. Skala Pengukuran dan Jumlah Respon Skala Likert. Jurnal Ilmu Pertanian dan Perikanan. 2(2):127-133.

Budiwan, J. 2018. Pendidikan orang dewasa (Andragogy). Jurnal Qalamuna. 2(2):107135.

Elizabeth, R. dan Rusdiana. 2012. Motivasi Petani dalam Pemeliharaan Usaha Ternak Ayam Kampung di Pedesaan. Workshop Nasional Unggas Lokal. 68-73.

Ijah, H. dan R.I. Altandjung. 2019. Determinasi Peluang Adopsi Teknologi Budidaya Ternak Ayam KUB di Papua Barat. Jurnal Pengkajian dan Pengembangan Teknologi Pertanian Badan Litbang Pertanian. 22 (2).

Sartika, T. 2017. Panen Ayam Kampung 70 Hari. Penebar Swadaya. Jakarta.

Sudana, W. dan K. Subagyono. 2012. Kajian faktor-faktor penentu adopsi inovasi pengelolaan tanaman terpadu padi melalui sekolah lapang pengelolaan tanaman terpadu. Jurnal Pengkajian dan Pengembangan Teknologi Pertanian. 15(2):95-106.

Tim Pusat Studi Gempa Nasional. 2018. Kajian Gempa Palu Provinsi Sulawesi Tengah 28 September 2018 (M 7.4). Pusat Penelitian dan Pengembangan Perumahan dan Pemukiman Badan Penelitian dan Pengembangan Kementerian Pekerjaan Umum dan Perumahan Rakyat. Bandung.

Tondi, K.M. 2019. Deskripsi dampak gempa bumi dan likuifaksi terhadap petani di Desa Jono Oge Kabupaten Sigi Propinsi Sulawesi Tengah. Jurnal Agroland: Jurnal Ilmu-Ilmu Pertanian. 26(2):148157.

Paulus, A.L., W.M. Wangke dan V.R.B. Moniaga. 2015. Kontribusi usahatani kacang panjang terhadap pendapatan rumah tangga petani di Desa Warembungan Kecamatan Pineleng. AgriSosioekonomi. 11(3):53-62.

Prawiranegara, D., Liferdi dan B. Sunandar. 2019. Strategi pengembangan Ayam KUB pada program bekerja di Kabupaten Garut Provinsi Jawa Barat. Creative Research Journal. 5(1):41-54.
Urfa, S., H. Indrijani, dan W. Tanwiriah. 2017. Model kurva pertumbuhan ayam Kampung Unggul Balitnak (KUB) umur 0-12 minggu. Jurnal Ilmu Ternak Universitas Padjadjaran. 17(1):59-66.

Umaroh, R.A. dan S. Ritohardoyo. 2016. Strategi penghidupan masyarakat korban bencana tanah longsor (kasus: Kecamatan Banjarmangu dan Kecamatan Karangkobar, Kabupaten Banjarnegara). Jurnal Bumi indonesia. 5 (4). 